\title{
Organizational Learning, Agility and Social Technologies in Contemporary Workplaces
}

\author{
Kati Tikkamäki and Nicholas Mavengere \\ CIRCMI, School of Information Sciences, University of Tampere, Finland \\ \{kati.tikkamaki, nicholas.mavengere\} @uta.fi
}

\begin{abstract}
The contemporary workplaces face demanding challenges, such as expectations to be agile, competitive, efficient and adept to using employee knowledge. There are several required virtues in order to have a conductive workplace, for example, organizational learning and agility. The discussion forum aimed to bring out the inter-related roles of organizational learning, agility and social technologies in modern workplaces. The working methods in the discussion group consisted of brainstorming, learning café and mind mapping. Work organizations are examined as potential but contradictory learning spaces. Agility is the ability of an organization to rapidly respond to changes in demand. Organizational learning and agility are increasingly enabled by social technologies. The social technologies advances in the modern society are rigorously changing the contemporary workplaces. Social technologies include communication and interactive mechanisms embedded on the internet, such as, wikis and blogs. We suggest that organizational learning and agility might be increasingly enabled by social technologies. However, social technologies have a potential to enable and disable organizational learning. The usage of social technology and the level of agility are depending on the contextual factors like type of organization, field of profession and type of work. Different types of organizations and work have different needs for using social technologies as a driving force of organizational learning and agility.
\end{abstract}

Keywords: Organizational learning, agility, social technologies, modern workplaces, conference discussion session.

\section{Introduction}

This is a report of the OST'12 conference discussion session titled organizational learning, agility and social technologies in contemporary workplaces. The aim of the discussion was to bring out the inter-related roles of organizational learning, agility and social technologies in modern workplaces. The contemporary workplaces face demanding challenges, such as expectations to be agile, competitive, efficient and adept to using employee knowledge. There are several required virtues in order to have a conductive workplace, for example, organizational learning and agility. However, organizational learning and agility are intertwined in a complex way. And the complexity is even increased by the emergent of new social technologies. Moreover, both academics and practitioners have not agreed on a uniform definition 
of these concepts. To further explore these novice themes the discussions were guided by the following questions:

1. What is the role of social technologies in organizational learning?

2. How does organizational learning impact agility?

3. How can social technologies and organizational learning enhance agility in contemporary workplaces?

\section{Working Methods of the Discussion Session}

The working methods in the discussion group consisted of brainstorming, learning café and mind mapping. The number of participants were eleven of which two were also facilitators of the session. Participants of the session were: Jane Andersen (Denmark), Danel Apse (Estonia), Urmas Heinaste (Estonia), Jörgen Jaanus (Estonia), Tobias Ley (Estonia/Germany), Edmund Laugasson (Estonia), Juhani Linna (Finland), Birgy Lorenz (Estonia), Nicholas Mavengere (rapporteur, Finland), Heiki Tähis (Estonia) and Kati Tikkamäki (chair, Finland). After the introducing session (by peer interviewing) initial brainstorming took place in small workgroups. Groups defined and clarified the relationships between social technologies, organizational learning and agility by writing down the keywords and key ideas based on their knowledge and experiences. On the second day the group work was outlined by central ideas based on two scientific articles [1,2]. Then participants formulated their ideas more precisely in the Learning Café. Participants were divided into two groups and they were asked to write down on the table cloths their views about the social technologies' role in enhancing agility and organizational learning in contemporary workplaces. Groups changed the table after about 30 minutes and continued brainstorming on the table cloths. Finally, there was an open discussion where groups presented the ideas from the table cloths. On the third day we summarized the discussions by creating mind/concept maps of what we had learned about the relationships between social technologies, organizational learning and agility.

\section{Organizational Learning, Agility and Social Technologies}

Organizational memory is crucial concept from the point of view of organizational learning and agility. It consists e.g. of data warehousing, expert systems, best practice databases, Intranet and Internet [2]. Organizational memory includes many types of knowledge based on Blackler [3] definition like: embrained, embodied, encultured, embedded and encoded knowledge. Embrained knowledge includes parts of propositional knowledge which are internalized facts and principles. Embodied knowledge appears in forms of activity that include elements of tacit knowledge. Encultured knowledge refers to the processes of achieving shared understandings and negotiation. Embedded knowledge is situated in the products, prototypes, technologies, tools and buildings in an organization (cf. practical knowledge). Encoded knowledge is symbolic and it has usually a written nature (cf. theoretical knowledge). For example, it takes a form of instructions, handbooks, written plans or 
theoretical models [3]. Knowledge is encoded in symbolic forms made by human beings and embedded in concrete objects made by nature or by human beings. It is embrained and embodied in individuals and collectives and it takes the form of encultured knowledge also. Organizational memory can take a form of story, document, data base or habit/routine.

Social technologies can facilitate the access to and the usage of that memory and knowledge resources. Social technologies can be an important ingredient in the design of organizational learning infrastructure and facilitator of the learning processes like storing, accessing and revising the elements of organizational memory [2]. Social technologies are used in many contemporary professions and work contexts in communicating, finding information and collaborating. In this case social technologies are defined based on McKinsey report [4] as: "the products and services that enable social interactions in the digital realm, and thus allow people to connect and interact virtually" (pg. 4).

Organizational learning should be enhanced through systems that support communication and discourse [2]. Based on Wenger [5] communities of practice organizations can be viewed as communities of learning [6] where co-creation, sharing and negotiation of knowledge are emphasized. Social technologies may enhance these social processes by making possible to share information and tell stories with members of different communities, comparing experiences with others, building new relations and forming groups for different purposes.

Participants of the discussion group had challenges in defining the concept of agility. There exist different definitions of agility in the literature. Agility is the organization's ability to rapidly respond to changes in demand. Based on Li, Nagel and Sun [1] agility can be defined by four dimensions like social agility, organizational agility, agile communities and ecosystem agility. Social agility includes individual and team performance improvement by easier and faster interactivity on common business objectives. Organizational agility is based on the premises of boundary-less organizational structure which enables knowledge sharing and collaboration both internally, with other divisions and externally with business partners. Agile communities are societies built based on social and organizational agility. Ecosystem agility includes the use of social technologies in business to sense and manage the relations in their business ecosystems to gain competitive advantage.

Agility can be seen as an ability of an organization to sense (know) the business environment (customers, competitors, suppliers etc.) and respond change in time- So, it is more than flexibility - it is responding in a "right" place in a "right" time. Based on discussion sessions' discussions, being agile requires employees' and managers' ability to learn as well as taking care of the learning processes. In practice it means learning from experience/history by breaking up routines and creating new ones, creating possibilities for participation, creating spaces and forums for creating and sharing of knowing, utilizing social interaction and social support and taking time for reflective processes $[6,5,3]$.

We suggest that organizational learning and agility might be increasingly enabled by social technologies. However, ironically organizational learning capacity and implementation of social technologies that enable organizational learning depends on 
organization's present capacity to learn. Therefore, social technologies have a potential to enable and disable organizational learning. One risk in organizing practices heavily on social technologies is that organization and employees might become too dependent on formal systems and they might overlook the potential of less informal usage of organization memory [2]. The added value of social technologies and its' effects on organizations agility are depending on changes in organizational structures, processes, practices and culture [4].

\section{Conclusion}

Organizational learning, agility and social technologies are intertwined in a complex way. It is essential to note the driver in each case, either technology or agility or organizational learning? What is the main focus in utilizing social technologies and developing organization's ability to learn and be agile? Is it in increasing business and competitive intelligence, in increasing the knowledge sharing and co-creation and/or in collecting information and making it easily available? Learning is enhanced through community-based and explorative learning. Generating and sharing of knowledge were seen essential. The challenge is to create spaces and forums for knowledge co-creation and using organizational memory in a meaningful ways as a source of learning. But in what extent these processes of knowledge construction and sharing should be enhanced through social technologies?

It was suggested that social technologies should enhance organizational learning which then leads to organizations' agility. Social technologies should be "easy to use", flexible and handy when enhancing learning as well as usage and construction of organizational memory. It is noted that there is remarkable potential (organizational memory \& customers) as well as challenges in utilizing social technologies. However, it is important to examine the added value of social technologies in work context. In general, the benefits of social technologies include quick exchange of experiences and knowledge, easy access to information, allowing many people to access information simultaneously and making it easier to reach people. In addition to this social technologies offer possibilities, such as, breaking up old routines and building up new ones, linking organization to customers e.g. through customer-driven innovation, generating of new ideas and processing them on the community level, connecting dispersed people, finding answers quickly and allowing openness. These processes were seen to enable sharing and thus learning.

But the impact of social technologies on agility and organizational learning is limited if employees do not have skills and motivation to use social technologies. There is often need for training and creation of collective principles of using social technologies as a part of work processes in the organizations. Collective negotiation processes and discussion forums ensure added value for utilizing new technology as part of work processes as well as creation of collective principles concerning the new work practices. Employees and managers preconceptions, attitudes and reactions are reasonable to make visible and open for discussions. Utilization of social technologies calls for transparency of agreements and practices. Employees also need to have skills 
enough for utilizing social technologies which can be reached through facilitated peer learning and internal training.

Customers are increasingly becoming powerful in the current business environment. In agreement to Sambamurthy, Bharadwaj and Grover [7] the role of customers could be summarized as "a source of innovation ideas, as a co-creator in the development and design of innovative products and services, and as a user in testing the product or in helping other users learn about the new product or service" (pg. 245). However, the usage of social technology and the level of agility are depending on the contextual factors too like type of organization, field of profession and type of work. Different types of organizations and work have different needs for using social technologies as a driving force of organizational learning and agility. The justifications for utilizing social technologies should be based on missions and visions of an organization. Referring to one discussion session's participant's vision: "Social technologies should be an integrated part of enterprise resource planning (ERP). It leads to integration of business processes and learning which in turn has the potential to positively influence agility."

\section{References}

1. Li, Q., Nagel, N.R., Sun, L.: Migrating to Agility 2.0: How Social Computing Creates Strategic Value. Organizational Dynamics 40, 119-126 (2011)

2. Robey, D., Boudreau, M.-C., Rose, G.: Information technology and organizational learning: a review and assessment of research. Accounting Management and Information Technologies 10, 125-155 (2000)

3. Blackler, F.: Knowledge Work and Organisations: An Overview and Interpretation. Organization Studies 16(6), 1021-1046 (1995)

4. Chui, M., Manyika, J., Bughin, J., Dobbs, R., Roxburgh, C., Sarrazin, H., Sands, G., Westergren, M.: The social economy: Unlocking value and productivity through social technologies. McKinsey Global Institute (2012)

5. Wenger, E.: Communities of Practice. Learning, Meaning and Identity. Cambridge University Press, New York (1999)

6. Tikkamäki, K.: Työn ja organisaation muutoksissa oppiminen - etnografinen löytöretki työssä oppimiseen (Learning in Changing Work and Organizational Contexts Ethnographical Discovery on Workplace Learning.), Doctoral dissertation, University of Tampere, School of Education. University Press, Tampere (2006)

7. Sambamurthy, V., Bharadwaj, A., Grover, V.: Shaping Agility through Digital Options: Reconceptualizing the Role of Information Technology in Contemporary Firms. MIS Quarterly 27(2), 237-263 (2003) 